\title{
NOVAS PERSPECTIVAS
}

A Geo UERJ é uma publicação semestral do Instituto de Geografia e Programa de Pós-Graduação em Geografia da Universidade do Estado do Rio de Janeiro que publica trabalhos inéditos de revisão crítica, resultados de pesquisas de natureza empírica, experimental ou conceitual sobre temas pertinentes à Geografia e áreas afins, prezando por sua identidade a revista se mantém atemática.

No ano passado a Geo UERJ completou vinte anos de existência em virtude disso algumas modificações serão implementadas até o final do ano de 2018: a primeira delas é a inclusão do DOI nos textos publicados de 2009 em diante, a informação está disponível no resumo de cada texto no site da revista; a submissão de textos permanece em fluxo contínuo; disponibilizaremos todo o conteúdo elaborado ao longo desses anos, desde o número um até o atual; o site da revista foi alterado para dar mais clareza a informações bem como um layout mais moderno; foi criada uma fanpage para a divulgação dos textos no Facebook; no último ano além das bases de dados em que já estava indexada a saber, Geodados, Latindex, Sumário.org, Periódicos Capes, Jounals for Free, Diadorim, REDIB, Google Scholar, Cengage Learning, DOAJ, Livre, Road, DRJI, OAJI, Jounals TOCs a revista passou a figurar na LatinRev e no Emerging Sources Citation Index (ESCI) da Web of Science as indexações auxiliam na divulgação da Geo UERJ e reconhecimento da importância da revista junto ao meio acadêmico.

A submissão é através do Portal de Publicações Eletrônicas da UERJ, que utiliza o Open Journal System (OJS), os artigos são selecionados através da avaliação duplo-cega, por no mínimo dois avaliadores. A publicação é de acesso aberto estando licenciada coma a Creative Commons BY-NC-SA que significa que o texto pode ser compartilhado e modificado desde que a fonte seja citada, o material publicado não pode ser utilizado para fins comerciais e as derivações do material original devem ser compartilhadas utilizando o mesmo tipo de licença. 
A partir do presente número os artigos serão publicados conforme forem avaliados e aprovados, com isso os processos editoriais foram revistos para que os textos sejam disponibilizados com mais agilidade e mantendo assim a periodicidade em dia.

Ao longo desses anos de existência o apoio institucional foi de suma importância para a manutenção e melhoria dos processos de editoria da revista. Houve uma adequação da revista junto aos critérios nacionais e internacionais esperados de uma publicação científica.

Com todas as ações elencadas esperamos que a Geo UERJ continue sendo um canal de disseminação do conhecimento de conteúdos relevantes para o debate da área de Geografia e áreas afins, buscando a manutenção da qualidade e periodicidade além de maior amplitude de bases de dados e indexadores.

Glaucio Jose Marafon

Antonio Soares da Silva

Mônica Sampaio Machado

Editores da Revista Geo UERJ 